\section{Pengaruh Trust Dan Perceived Ease Of Use Terhadap Intention Kaum Milenial Dalam Menggunakan Aplikasi E-Commerce Shopee Yang Dimediasi Oleh Perceived Of Usefulness}

Digital Marketing and Millenial

Consumers

\section{Melaningtyas Tesalonika $\mathbf{H}$, Ambar Lukitaningsih, Bernadetta Diansepti M}

${ }^{123^{2}}$ Fakultas Ekonomi Universitas Sarjanawiyata Tamansiswa, Yogyakarta, Indonesia

Email : Melaningtyas55@gmail.com

\begin{abstract}
This study aims to determine the influence of Trust, Perceived ease of use on Intention with Perceived of Usefulness as Mediation for millennials in using application-based transportation. Many millennials currently use the Shopee e-commerce application. In Indonesia alone, there are various kinds of well-known e-commerce in this community such as Shopee, Pedia Shop, Buka, Lazada and others. Sometimes we get confused between these e-commerce. That's why in this study, researchers want to know what factors influence the millennial generation. Researchers narrow down three variables, trust, perceived ease of use, and perceived usefulness. This research is using quantitative type of reasearch and choosing 100 people (male \& female, 18-26 years old, and uses Shopee e-commerce) assubjects research. Researchers used the SPSS application to test the results of the study. The results showed that the most influential factor in influencing the intention to use application-based transportation was perceived usefulness, followed by perceived ease of use, and the last one that had the least effect was trust.
\end{abstract}

Keywords: e-commerce, perceived usefulness, sense of ease of use, and trust

\begin{abstract}
ABSTRAK
Penelitian ini bertujuan untuk mengetahui pengaruh Trust, Perceived kemudahan penggunaan terhadap Intention with Perceived of Usefulness as Mediation pada milenial dalam menggunakan transportasi berbasis aplikasi. Banyak kaum milenial saat ini menggunakan aplikasi e-commerce Shopee. Di Indonesia sendiri terdapat berbagai macam e-commerce ternama di komunitas ini seperti Shopee, Pedia Shop, Buka, Lazada dan lain-lain. Terkadang kita bingung antara e-commerce ini. Oleh karena itu dalam penelitian ini peneliti ingin mengetahui faktor-faktor apa saja yang mempengaruhi generasi milenial. Peneliti mempersempit tiga variabel, kepercayaan, persepsi kemudahan penggunaan, dan kegunaan yang dirasakan. Penelitian ini menggunakan jenis penelitian kuantitatif dan memilih 100 orang (laki-laki \& perempuan, 18-26 tahun, dan menggunakan Shopee e-commerce) sebagai subjek penelitian. Peneliti menggunakan aplikasi SPSS untuk menguji hasil penelitian. Hasil penelitian menunjukkan bahwa faktor yang paling berpengaruh dalam mempengaruhi niat menggunakan transportasi berbasis aplikasi adalah persepsi kegunaan, disusul persepsi kemudahan penggunaan, dan terakhir yang memiliki pengaruh paling kecil adalah kepercayaan.
\end{abstract}

Kata Kunci : e-commerce, persepsi kegunaan, kemudahan penggunaan, dan kepercayaan

\section{PENDAHULUAN}

Pada masa ini, bersebelahan dengan kalangan milenial identik dengan pertumbuhan teknologi yang sangat pesat. Penyebaran data terus menjadi besar, kemajuan terjalin

\section{JIMKES}

Jurnal Ilmiah Manajemen Kesatuan
Vol. 9 No. 1,2021 pp. $1-10$
IBI Kesatuan ISSN $2337-7860$ E-ISSN 2721 - 169X 
Digital Marketing and Millenial

Consumers

dimana- mana. Pertumbuhan tersebut tidak cuma terdapat pada satu aspek dalam kehidupan, tetapi terdapat di bermacam aspek kehidupan. Salah satu pertumbuhan yang sangat terasa kehadirannya yaitu e-commerce. Kita ketahui saat ini kalau salah satu karakteristik khas dari generasi milenial adalah perilaku dasar mereka yang menggemari kepraktisan serta seluruh suatu yang personal (Eriska, 2018).

E-commerce merupakan suatu konsep baru yang dapat ditafsirkan bagaikan proses jual beli ataupun pertukaran produk, jasa serta data lewat jaringan Internet. Proses penjualan serta pembelian yang dicoba lewat internet pastinya lebih efektif serta kilat dan gampang dalam pemasaran produk serta jasa yang dibuat oleh industri. Salah satu e-commerce di Indonesia yaitu Shopee. Shopee merupakan web yang sangat terkenal sebab web ini sediakan berbagai macam benda. Shoppe ialah salah satu tempat transaksi jual beli online yang sangat terkenal di Indonesia. Ada banyak benda yang dijual di Shopee yang terdiri dari sebagian jenis semacam jual beli santapan, minuman, gadget, baju, sepatu, koleksi, mainan, dsb. Pada web tersebut memiliki data yang lengkap, sebab telah tercantum foto produk, kriteria produk, harga produk, sampai posisi penjual. Sehingga konsumen bisa berbicara secara langsung dengan penjual. Semenjak didirikannya, Shopee sukses merespon kebutuhan pasar hingga style hidup modern berbelanja online. Shopee menduduki pengunjung web bulanan tertinggi pada tahun 2020 yaitu sebesar 93.440 .300 Pengunjung dan pengunduhan aplikasi nomor satu di play store dan app store, (konsumendigital.com).

Pengguna berpikiran bahwa Shopee bisa dipercaya (Trust) mudah digunakan (perceived ease of use) serta juga bermanfaat untuk dirinya (Perceived Usefulness), sehingga Intention pengguna untuk mengakses Shopee juga hendak bertambah (Winayu, 2013). Dengan begitu dapat disimpulkan bahwa minat pengguna untuk mengakses suatu situs e-commerce merupakan aspek penting dalam memastikan kesuksesan situs $e$-commerce tersebut. Semakin banyak pengguna yang berminat mengakses ataupun bertransaksi $e$-commerce Shopee, hingga terus menjadi sukses pula situs tersebut, berlaku pula sebaliknya. Milllenial generation atau generasi Y, yang biasa disebut generation me atau echo boomers. Secara harfiah memang tidak adea demografi khusus dalam menentukan kelompok geneerasi milenial. Para pakar menggolongkan generasi Y pada awal dan akhir. Penggolongan generasi $\mathrm{Y}$ terbentuk bagi mereka yang lahir 1980-1990, atau pada awal tahun 2000, dan seterusnya (www.kominfo.com). Dapat disimpulkan mahasiswa termasuk dalam kaum millenial yang dimana mahasiswa merupakan konsumen yang aktif dan kritis dalam menentukan tempat berbelanja yang terbaik untuk mereka. Gaya hidup belanja online di kalangan mahasiswa kini makin populer karena e-commerce lebih banyak memberikan pilihan produk dengan harga yang bervariasi (Winayu, 2013). Pengguna terhadap e-commerce khususnya Shopee, dalam hal ini Mahasiswa S1 Prodi Manajemen di Universitas Sarjanawiyata Tamansiswa berminat menggunakan Shopee atau sebaliknya, dilihat dari faktor-faktor yang mungkin berpengaruh signifikan dalam menggunakan e-commerce seperti tingkat Ttrust, Perceived Ease of Use, Perceived Usefulness dan Intention.

Mayer et al. (1995) dalam (Winayu, 2013) mendefinisikan kepercayaan (trust) sebagai keinginan seseorang untuk peka terhadap tindakan orang lain berdasarkan pada harapan jika orang lain hendak melaksanakan tindakan tertentu pada orang yang mempercayainya, tanpa tergantung pada kemampuannya untuk mengawasi serta mengendalikannya. Menurut Pavlou (2003) dalam (Winayu, 2013) terdapat tiga macam indikator untuk mengukur tingkat kepercayaan (trust) terhadap suatu situs e-commerce, yaitu: Dapat dipercaya, Menjaga janji dan komitmen, Terdapat pemikiran untuk mempercayai. Menurut Susanto Aljoza (2015) dalam (Suryani, 2019) perceived ease of use didefinisikan sebagai kemudahan yang dirasakan oleh pengguna dari suatu sistem serta bebas dari usaha. Sehingga perceived ease of use merupakan sesuatu kepercayaan akan kemudahan pengunaan dari suatu layanan produk yang didapatkan (Priambodo \& Prabawani, 2016). Berikut ini merupakan pembagian ukuran persepsi kemudahan menurut Venkatesh dan Davis (2000) dalam (Winayu, 2013) yakni: Interaksi individu 
dengan sistem jelas serta mudah dimengerti, Tidak dibutuhkan banyak usaha untuk berinteraksi dengan sistem tersebut, Sistem mudah digunakan dan Mudah mengoperasikan sistem sesuai dengan apa yang ingin individu kerjakan. Menurut Davis (1989) dalam (Kanchanatanee, Suwanno, \& Jarernvongrayab, 2014) Perceived of Usefulness mengacu pada tingkat kepercayaan individu bahwa penggunaan teknologi akan meningkatkan prestasi kerja. Davis mendefinisikan persepsi mengenai kegunaan (usefulness) ini berdasarkan definisi dari kata useful yaitu "capable of being used advantageously", atau dapat digunakan untuk tujuan yang menguntungkan. Terdapat beberapa dimensi Perceived of Usefulness menurut Venkatesh dan Davis (2000) dalam (Winayu, 2013) yaitu: Penggunaan sistem mampu meningkatkan kinerja individu, Penggunaan sistem mampu menambah tingkat produktifitas individu, Penggunaan sistem mampu meningkatkan efektifitas kinerja individu , Penggunaan sistem bermanfaat bagi individu.

Sprotles dan Kendall (1986) dalam (Ulaan, Pangemanan, \& Lambey, 2016) mengatakan bahwa Intention adalah orientasi mental yang mencirikan pendekatan konsumen dalam membuat pilihan. Instrumen pengukur minat menggunakan (intention to use) meliputi 3 perihal (Kharismayanti Rahma, 2012) dalam (Winayu, 2013), yaitu: Keinginan untuk menggunakan, Selalu mencoba menggunakan dan Berlanjut di masa yang akan datang

\section{Penelitian Terdahulu}

Asrukin (2001) telah melakukan penelitian dengan judul sikap mahasiswa terhadap fasilitas dan pelayanan Perpustakaan IKIP Malang. Metode penelitian deskriptif kuantitatif, dianalisis dengan Chi-Square, Product Moment Correlation. Data diperoleh melalui kuesioner dari 156 orang mahasiswa yang dijadikan sampel. Hasil penelitian membuktikan terdapat hubungan yang positif antara sikap mahasiswa terhadap fasilitas perpustakaan, dan tidak terdapat hubungan antara sikap mahasiswa terhadap pelayanan perpustakaan dalam frekuensi peminjaman buku. Samosir (2004) dengan judul penelitian pengaruh kualitas pelayanan terhadap kepuasan mahasiswa dalam menggunakan Perpustakaan USU Medan. Metode penelitian deskriptif kuantitatif yang bertujuan untuk menggambarkan persepsi pengguna terhadap kualitas jasa layanan perpustakaan dalam lima dimensi yaitu kehandalan, ketanggapan, jaminan, empati, dan bukti fisik. Diperoleh melalui kuesioner dari 393 responden yang dijadikan sampel. Hasilnya membuktikan bahwa kualitas pelayanan secara serempak berpengaruh signifikan terhadap kepuasan mahasiswa, secara parsial dimensi bukti langsung, kehandalan, ketanggapan dan empati berpengaruh signifikan terhadap kepuasan mahasiswa, sedangkan dimensi jaminan tidak berpengaruh secara signifikan.

\section{Kerangka Pemikirian}

Kerangka pemikiran dalam penelitian ini adalah sebagai berikut :

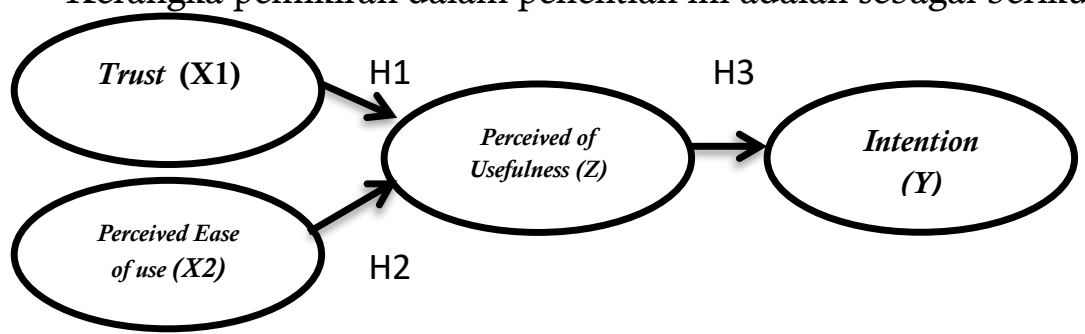

\section{Gambar 1. Kerangka Pemikiran}

\section{Hipotesis Penelitian}

Berdasarkan tujuan penelitian, perumusan masalah dan kerangka pemikiran di atas, peneliti memberikan hipotesis adalah sebagai berikut, yaitu :

H1 : Trust berpengaruh positif dan signifikan terhadap Perceived of Usefulness

$\mathrm{H} 2$ : Perceived Ease of Use berpengaruh positif dan signifikan terhadap Perceived of Usefulness

$\mathrm{H} 3$ : Perceived of Usefulness berpengaruh positif dan signifikan terhadap Intention

Digital Marketing and Millenials

Consumers 
Digital Marketing and Millenial Consumers

\section{METODOLOGI PENELITIAN}

Penelitian ini dilakukan pada mahasiswa S1 Program Studi Manajemen, Fakultas Ekonomi, Universitas Sarjanawiyata Tamansiswa. Waktu penelitian dilaksanakan pada bulan November 2020 untuk uji coba terhadap instrumen penelitian dan membagikan kuesioner, dan November 2020 melakukan analisis data dan menyusun laporan penelitian. Metode pengumpulan data yang digunakan dalam penelitian ini adalah dengan menggunakan angket atau kuesioner. Populasi yang terdapat dalam penelitian ini berjumlah 2.822 orang dan presisi yang ditetapkan atau tingkat signifikansi 0,1 , maka besarnya sampel pada penelitian ini yang ditetapkan dengan rumus slovin diperoleh hasil 96,57 dan dibulatkan menjadi 100 jadi, jumlah keseluruhan responden dalam penelitian ini adalah 100 orang. Pendekatan umum yang digunakan dalam penelitian ini adalah nonprobability sampling. Teknik yang dipakai adalah Purposive sampling dimana elemen populasi dipilih atas dasar kriteria tertentu.

Sumber data yang di gunakan dalam penelitian ini adalah data Primer. Data primer adalah data yang diperoleh langsung dari sumbernya, diamati dan dicatat untuk pertama kalinya (Marzuki, 2005). Data primer yang ada dalam penelitian ini adalah data-data dari kuisioner. Dalam penelitian ini, data primer didapat dari hasil pengisian kuesioner oleh konsumen Shopee mahasiswa Prodi Manajemen UST. Terdapat tiga jenis variabel dalam penelitian ini yaitu Variabel independent (bebas) : Trust (X1), Perceived Ease of Use (X2), Variabel Mediasi (Penghubung) : Perceived of Usefulness (Z) dan Variabel dependent (terikat) yaitu: Intention $(\mathrm{Y})$.

\section{HASIL DAN PEMBAHASAN}

\section{Karakteristik Responden}

1. Responden Berdasarkan Jenis Kelamin

Dari 100 responden, kebanyakan berjenis kelamin laki-laki yaitu sebanyak 26 dan yang berjenis kelamin perempuan sebanyak 74 .

Tabel 1 Karakteristik Responden berdasarkan Jenis Kelamin

\begin{tabular}{|c|c|c|c|c|c|}
\hline & ais Kelamin & Frequency & Percent & Valid Percent & Cumulative Percent \\
\hline \multirow[t]{3}{*}{ Valid } & Laki-laki & 26 & 26,0 & 26,0 & 26,0 \\
\hline & Perempuan & 74 & 74,0 & 74,0 & 100,0 \\
\hline & Total & 100 & 100,0 & 100,0 & \\
\hline
\end{tabular}

Sumber: Data primer diolah, 2020

2. Responden Berdasarkan Program Studi

Berdasarkan tabel 2 menunjukkan bahwa Prodi Manajemen yaitu 82 orang, sedangkan Prodi Akuntansi 18 orang.

Tabel 2 Karakteristik Responden berdasarkan Program Study

\begin{tabular}{|c|c|c|c|c|c|}
\hline \multicolumn{2}{|c|}{ Program Studi } & Frequency & Percent & $\begin{array}{c}\text { Valid } \\
\text { Percent }\end{array}$ & $\begin{array}{l}\text { Cumulative } \\
\text { Percent }\end{array}$ \\
\hline \multirow[t]{3}{*}{ Valid } & Manajemen & 82 & 82,0 & 82,0 & 82,0 \\
\hline & Akutansi & 18 & 18,0 & 18,0 & 100,0 \\
\hline & Total & 100 & 100,0 & 100,0 & \\
\hline
\end{tabular}

Sumber: Data primer diolah, 2020

3. Responden Berdasarkan Usia

Tabel 3 Karakteristik Responden berdasarkan Usia

\begin{tabular}{|l|r|r|r|r|r}
\hline Usia & Frequency & Percent & Valid Percent & Cumulative Percent \\
\hline Valid & $(13-20)$ Tahun & 13 & 13,0 & 13,0 & 13,0 \\
\cline { 2 - 6 } & $(21-23)$ Tahun & 80 & 80,0 & 80,0 & 93,0 \\
\cline { 2 - 6 } & $(24-26)$ Tahun & 7 & 7,0 & 7,0 & 100,0 \\
\cline { 2 - 6 } & Total & 100 & 100,0 & 100,0 & \\
\hline
\end{tabular}

Sumber: Data primer diolah, 2020 
Berdasarkan tabel 3 menunjukkan bahwa usia 18-20 tahun yaitu 13 orang, usia 21-23 tahun sebanyak 80 orang dan usia 24-26 tahun sebanyak 7 orang. Dilihat dari uji tabel karakteristik responden berdasarkan dengan usia umur 21-23 lebih banyak menggunakan e-commerce Shopee.

4. Respondes Berdasarkan Transaksi

Berdasarkan tabel 4 menujukan bahwa Transaksi berbelanja dalam 1 Tahun terakhir 1-5 kali yaitu 31 orang, transaksi 6-10 kali sebanyak 20 orang dan yang lebih dari 10 kali sebanyak 49 orang.

Tabel 4 Karakteristik Responden berdasarkan Transaksi

Transaksi

\begin{tabular}{l|r|r|r|r|r}
\hline Valid & $1-5$ kali & 31 & 31,0 & 31,0 & 31,0 \\
\cline { 2 - 6 } 6-10 kali & 20 & 20,0 & 20,0 & 51,0 \\
\cline { 2 - 6 } & Lebih 10 kali & 49 & 49,0 & 49,0 & 100,0 \\
\cline { 2 - 6 } & Total & 100 & 100,0 & 100,0 & \\
\hline
\end{tabular}

Sumber: Data Primer Diolah (2020)

\section{Hasil Penelitian}

Tabel 5 : Hasil uji Validitas dan Reabilitas Trust (X1)

\begin{tabular}{|c|c|c|c|c|c|}
\hline Variabel & Butir & r-hitung & Keterangan & $\begin{array}{c}\text { Koefisien Alpha } \\
\text { Cronbach }\end{array}$ & Keterangan \\
\hline Trust & 1 & 0,66 & Valid & \multirow{9}{*}{0,867} & \multirow{9}{*}{ Reliabel } \\
\hline & 2 & 0,778 & Valid & & \\
\hline & 3 & 0,843 & Valid & & \\
\hline & 4 & 0,838 & Valid & & \\
\hline & 5 & 0,780 & Valid & & \\
\hline & 6 & 0,780 & Valid & & \\
\hline & 7 & 0,789 & Valid & & \\
\hline & 8 & 0,830 & Valid & & \\
\hline & 9 & 0,805 & Valid & & \\
\hline
\end{tabular}

Pada tabel 5 dijelaskan bahwa variabel Trust memiliki nilai r-hitung lebih besar dar r-tabel = 0,1966 maka dikatakan valid, dan nilai Koefisien Alpha Cronbach memiliki nilai lebh dari 0,06 maka dari tu dikatakan reliabel.

Tabel 6 : Hasil Uji Validitas dan Reliabilitas Perceived Ease of Use (X2)

\begin{tabular}{|c|c|c|c|c|c|}
\hline Variabel & Butir & r-hitung & Keterangan & $\begin{array}{c}\text { Koefisien Alpha } \\
\text { Cronbach }\end{array}$ & Keterangan \\
\hline Perceived & 1 & 0,602 & Valid & \multirow{12}{*}{0,928} & \multirow{12}{*}{ Reliabel } \\
\hline \multirow{11}{*}{ Ease Of Use } & 2 & 0,691 & Valid & & \\
\hline & 3 & 0,772 & Valid & & \\
\hline & 4 & 0,792 & Valid & & \\
\hline & 5 & 0,781 & Valid & & \\
\hline & 6 & 0,844 & Valid & & \\
\hline & 7 & 0,779 & Valid & & \\
\hline & 8 & 0,770 & Valid & & \\
\hline & 9 & 0,737 & Valid & & \\
\hline & 10 & 0,694 & Valid & & \\
\hline & 11 & 0,698 & Valid & & \\
\hline & 12 & 0,777 & Valid & & \\
\hline
\end{tabular}

Sumber: Data primer diolah 2020

Pada tabel 6 dijelaskan bahwa variabel Perceived Ease of Use memiliki nilai r-hitung lebih besar dar r-tabel $=0,1966$ maka dikatakan valid, dan nilai Koefisien Alpha Cronbach memiliki nilai lebh dari 0,06 maka dari tu dikatakan reliabel. 
Digital Marketing and Millenial

Consumers

$\underline{6}$

Tabel 7 : Hasil Validitas dan Reabilitas Perceived of Usefulness

\begin{tabular}{|c|c|c|c|c|c|}
\hline Variabel & Butir & r-hitung & Keterangan & $\begin{array}{l}\text { Koefisien Alpha } \\
\text { Cronbach }\end{array}$ & Keterangan \\
\hline \multirow{12}{*}{$\begin{array}{l}\text { Perceived of } \\
\text { Usefulness }\end{array}$} & 1 & 0,710 & Valid & \multirow{12}{*}{0,923} & \multirow{12}{*}{ Reliabel } \\
\hline & 2 & 0,786 & Valid & & \\
\hline & 3 & 0,794 & Valid & & \\
\hline & 4 & 0,678 & Valid & & \\
\hline & 5 & 0,668 & Valid & & \\
\hline & 6 & 0,729 & Valid & & \\
\hline & 7 & 0,708 & Valid & & \\
\hline & 8 & 0,770 & Valid & & \\
\hline & 9 & 0,707 & Valid & & \\
\hline & 10 & 0,829 & Valid & & \\
\hline & 11 & 0,755 & Valid & & \\
\hline & 12 & 0,701 & Valid & & \\
\hline
\end{tabular}

Sumber: Data primer diolah 2020

Pada tabel 7 dijelaskan bahwa variabel Perceived of Usefulness memiliki nilai rhitung lebih besar dar r-tabel = 0,1966 maka dikatakan valid, dan nilai Koefisien Alpha Cronbach memiliki nilai lebh dari 0,06 maka dari tu dikatakan reliabel.

Tabel 8 : Hasil Validitas dan Reabilitas Intention

\begin{tabular}{|c|c|c|c|c|c|}
\hline Variabel & Butir & r-hitung & Keterangan & $\begin{array}{l}\text { Koefisien Alpha } \\
\text { Cronbach }\end{array}$ & Keterangan \\
\hline \multirow[t]{9}{*}{ Intention } & 1 & 0,709 & Valid & \multirow{9}{*}{0,912} & \multirow{9}{*}{ Reliabel } \\
\hline & 2 & 0,823 & Valid & & \\
\hline & 3 & 0,792 & Valid & & \\
\hline & 4 & 0,749 & Valid & & \\
\hline & 5 & 0,730 & Valid & & \\
\hline & 6 & 0,839 & Valid & & \\
\hline & 7 & 0,763 & Valid & & \\
\hline & 8 & 0,775 & Valid & & \\
\hline & 9 & 0,740 & Valid & & \\
\hline
\end{tabular}

Sumber: Data primer diolah 2020

Pada tabel 8 dijelaskan bahwa variabel Intention memiliki nilai r-hitung lebih besar dar r-tabel $=0,1966$ maka dikatakan valid, dan nilai Koefisien Alpha Cronbach memiliki nilai lebh dari 0,06 maka dari tu dikatakan reliabel.

\section{Persamaan I}

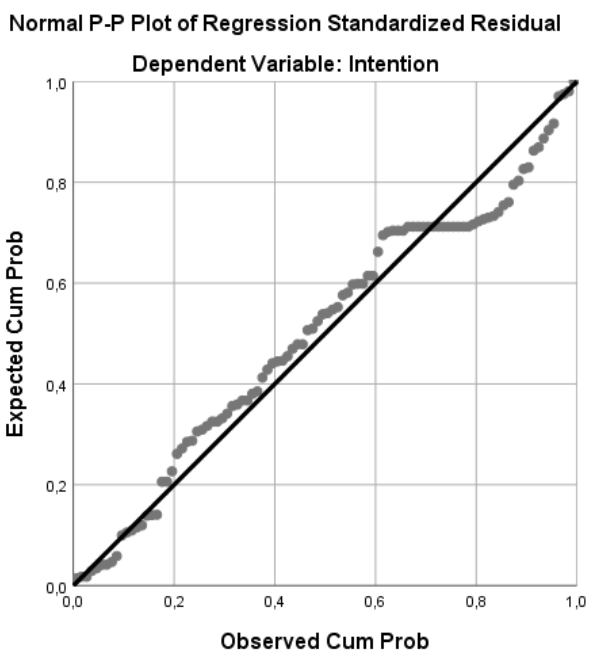

Persamaan II

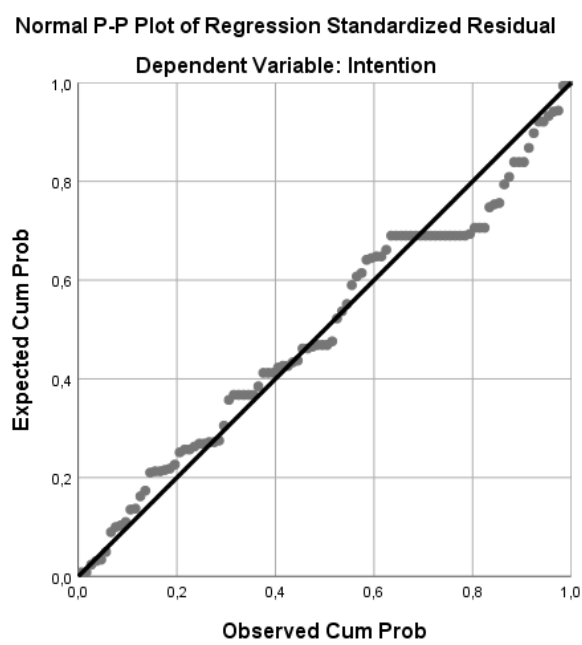

Gambar 1 : Hasil uji Normalitas 
Gambar 1 menunjukkan grafik normal plot terlihat data menyebar disekitar garis diagonal dan mengikuti arah garis diago nal atau grafik histogramnya menunjukkan pola berdistribusi normal, maka grafik normal plot memenuhi asumsi normalitas.

Tabel 9 : Hasil Uji Multikolinieritas

Persamaan I

\begin{tabular}{ll|r|r} 
& \multicolumn{2}{c|}{ Model } & \multicolumn{2}{c}{ Collinearity Statistics } \\
& Tolerance & \multicolumn{1}{c}{ VIF } \\
\hline 1 & & & \\
\hline & (Constant) &, 478 & 2,090 \\
\hline Trust &, 478 & 2,090 \\
\hline
\end{tabular}

Persamaan II

\begin{tabular}{ll|r|r} 
& \multicolumn{2}{c}{ Model } & \multicolumn{2}{c}{ Collinearity Statistics } \\
& Tolerance & \multicolumn{1}{c}{ VIF } \\
\hline $1 \quad$ (Constant) & & \\
\cline { 2 - 4 } & Trust &, 455 & 2,197 \\
\cline { 2 - 4 } & Perceived Ease Of Use &, 309 & 3,236 \\
\cline { 2 - 4 } & Perceived of Usefulness &, 363 & 2,756 \\
\hline
\end{tabular}

Tabel 9 menunjukkan semua nilai tolerance $>0,10$ atau nilai $\mathrm{VIF}<10$, sehingga tidak terjadi multikolinieritas.
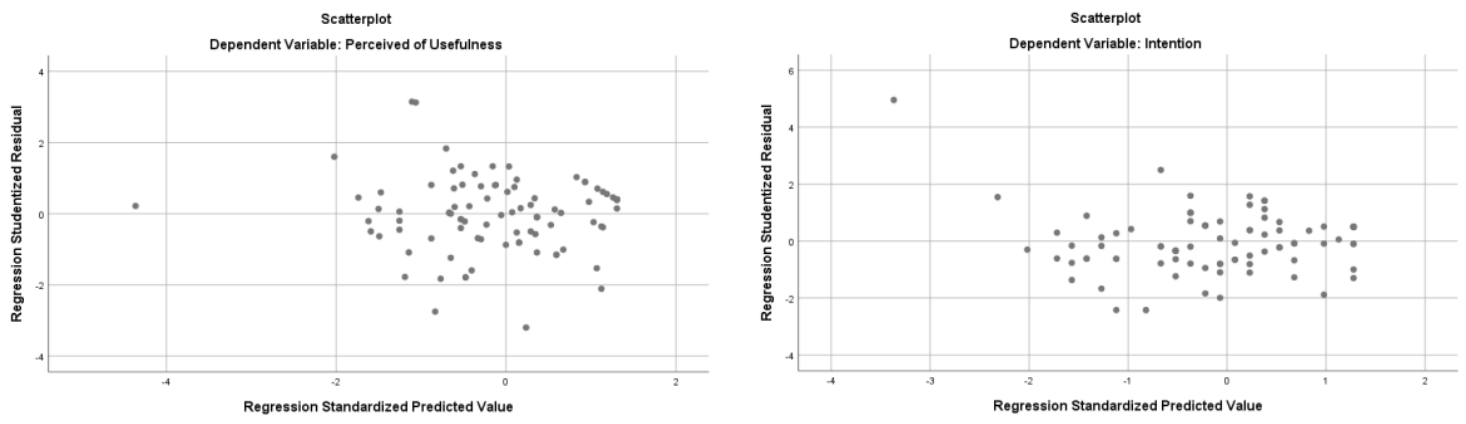

Gambar 2 : Hasil Uji Uji Heteroskedastisitas

Gambar 2 menjelaskan bahwa titik- titik pada grafik scatterplot tidak membentuk pola tertentu dan menyebar disekitar titik 0 (nol). Hal ini menunjukkan bahwa tidak terjadi heteroskedastisitas.

Tabel 10 : Hasil Analisis Regresi Berganda

\section{Persamaan I}

\begin{tabular}{|c|c|c|c|c|c|c|}
\hline \multirow{2}{*}{\multicolumn{2}{|c|}{ Model }} & \multicolumn{2}{|c|}{ Unstandardized Coefficients } & \multirow{2}{*}{$\begin{array}{c}\text { Standardized } \\
\text { Coefficients } \\
\text { Beta }\end{array}$} & \multirow[b]{2}{*}{$\mathrm{T}$} & \multirow[t]{2}{*}{ Sig. } \\
\hline & & $\mathrm{B}$ & Std. Error & & & \\
\hline 1 & (Constant) & 9,493 & 3,278 & & 2,896 & 005 \\
\hline & Trust & ,244 & ,110 & , 196 & 2,220 & ,029 \\
\hline & Perceived Ease Of Use & ,633 & ,087 & ,645 & 7,292 &, 000 \\
\hline
\end{tabular}

a. Dependent Variable: Perceived of Usefulness

Berdasarkan tabel diatas, maka dapat diperoleh persamaan regresi sebagai berikut: POU $=9,493+0,244 \mathrm{~T}+0,561$ PEOU + e. Persamaan tersebut menunjukkan Koefisien beta pada variabel Trust (X1) dan Perceived Ease of Use (X2) bernilai positif, maka berpengaruh positif terhadap variabel Perceived of Usefulness (Z).

Berdasarkan tabel, maka dapat diperoleh persamaan regresi II sebagai berikut: I $=12,403$ $-0,515 \mathrm{POU}+$ e. Persamaan tersebut menunjukkan Koefisien beta pada variabel Perceived of Usefulness $(\mathrm{Z})$ bernilai positif, maka berpengaruh positif terhadap variabel Intention $(\mathrm{Y})$
Digital Marketing and Millenials

Consumers 
Digital Marketing

and Millenial

Consumers

\section{Persamaan II}

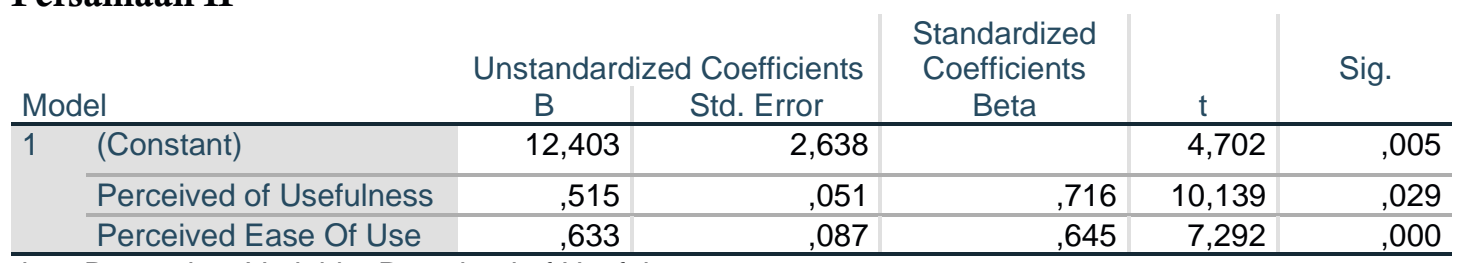

b. Dependent Variable: Perceived of Usefulness

\section{Hasil Uji T}

Pengaruh Trust terhadap Perceived of Usefulness

Hasil pengujian signifikansi menunjukkan bahwa variabel Trust terdapat nilai sig t sebesar 0,029 yang berarti 0,029 $<0,05$ dengan nilai t hitung 2,220 lebih besar dari t tabel 1,9811. Nilai tersebut dapat membuktikan bahwa Ho ditolak yang berarti bahwa Trust berpengaruh terhadap Perceived of Usefulness.

Pengaruh Perceived Ease of Use terhadap Perceived of Usefulness

Hasil pengujian signifikansi menunjukkan bahwa variabel Perceived Ease of Use terdapat nilai sig t sebesar 0,000 yang berarti $0,000<0,05$ nilai t hitung 7,292 lebih besar dari t tabel 1,98118. Nilai tersebut dapat membuktikan bahwa Ho ditolak yang berarti bahwa Perceived Ease of Use berpengaruh terhadap Perceived of Usefulness

Pengaruh Perceived of Usefulness terhadap Intention

Hasil pengujian signifikansi menunjukkan bahwa variabel Perceived of Usefulness terdapat nilai sig t sebesar 0,000 yang berarti $0,000<0,05$ nilai thitung 10,319 lebih besar dari t tabel 1,98118. Nilai tersebut dapat membuktikan bahwa Ho ditolak yang berarti bahwa Perceived of Usefulness berpengaruh terhadap Perceived Ease of Use

Tabel 11 Hasil Uji Koefisien Determinan $\left(\mathbf{R}^{2}\right)$

\section{Persamaan I}

\begin{tabular}{lc|c|c|c} 
Model & $\mathrm{R}$ & R Square & $\begin{array}{c}\text { Adjusted R } \\
\text { Square }\end{array}$ & $\begin{array}{c}\text { Std. Error of the } \\
\text { Estimate }\end{array}$ \\
\hline 1 &, $798^{\mathrm{a}}$ &, 637 &, 630 & 4,060 \\
\hline a. Predictors: (Constant), Trust, Perceived Ease of use &
\end{tabular}

\begin{tabular}{|c|c|c|c|c|}
\hline \multicolumn{5}{|c|}{ Persamaan II } \\
\hline Model & $\mathrm{R}$ & R Square & $\begin{array}{l}\text { Adjusted R } \\
\text { Square }\end{array}$ & $\begin{array}{l}\text { Std. Error of the } \\
\text { Estimate }\end{array}$ \\
\hline 1 &, $716^{\mathrm{a}}$ & ,512 & ,507 & 3,374 \\
\hline
\end{tabular}

Dari tabel 11 menunjukkan adjusted $R$ square pada persamaan 1 nilai adjusted $R$ square sebesar 0,630 hal ini berarti 63\% variabel Perceived of Usefulness dipengaruhi Trust dan Perceived Ease of Use sisanya $37 \%$ dipengaruhi oleh variabel lain. Adjusted $R$ square persamaan 2 adjusted $R$ square sebesar 0,507 hal ini berarti 50,7\% variabel Intention dipengaruhi Perceived of Usefulness sisanya 40,3\% dipengaruhi oleh variabel lain.

\section{Pembahasan}

Pengaruh Komunikasi Trust terhadap Perceived of Usefulness.

Berdasarkan dari uji persial (t hitung) Trust menghasilkan t hitung sebesar 2,222 dengan signifikansi 0,029 . Hal ini menunjukkan bahwa Trust berpengaruh positif dan signifikan terhadap Perceived of Usefulness karena nilai signifikansinya kurang dari 0,05. Maka hipotesis yang menyatakan bahwa Trust berpengaruh positif dan signifikan terhadap Perceived of Usefulness "terbukti". Hasil penelitian ini juga mendukung penelitian yang sudah dilakukan oleh (Eriska, 2018) menyatakan bahwa terdapat pengaruh positif dan signifikan antara Trust terhadap Perceived of Usefulness

Pengaruh Komunikasi Perceived Ease of Use terhadap Perceived of Usefulness.

Berdasarkan dari uji persial ( $\mathrm{t}$ hitung) Perceived Ease of Use menghasilkan $\mathrm{t}$ hitung sebesar 7,292 dengan signifikansi 0,000. Hal ini menunjukkan bahwa Perceived Ease of Use berpengaruh positif dan signifikan terhadap Perceived of Usefulness karena nilai signifikansinya kurang dari 0,05. Maka hipotesis yang menyatakan bahwa Perceived Ease 
of Use berpengaruh positif dan signifikan terhadap Perceived of Usefulness "terbukti". Hasil penelitian ini juga mendukung penelitian yang sudah dilakukan oleh (Eriska, 2018) menyatakan bahwa terdapat pengaruh positif dan signifikan antara Perceived Ease of Use terhadap Perceived of Usefulness.

\section{Pengaruh Komunikasi Perceived of Usefulness terhadap Intention}

Berdasarkan dari uji persial ( $\mathrm{t}$ hitung) Perceived of Usefulness menghasilkan $\mathrm{t}$ hitung sebesar 10,319 dengan signifikansi 0,000. Hal ini menunjukkan bahwa Perceived of Usefulness berpengaruh positif dan signifikan terhadap Intention karena nilai signifikansinya kurang dari 0,05 . Maka hipotesis yang menyatakan bahwa Perceived of Usefulness berpengaruh positif dan signifikan terhadap Intention "terbukti". Hasil penelitian ini juga mendukung penelitian yang sudah dilakukan oleh (Eriska, 2018), (Winayu, 2013), (Aditya \& Wardhana, 2016), (Bangkara, Putu, \& Harta, 2016) dan (Puspitasari \& Briliana, 2018) menyatakan bahwa terdapat pengaruh positif dan signifikan antara Perceived of Usefulness terhadap Intention.

\section{PENUTUP}

Berdasarkan hasil penelitian dan pembahasan penelitian diatas dapat disimpulkan sebagai berikut:

1. Terdapat pengaruh positif Trust terhadap Perceived of Usefulness dalam menggunakan e-commerce Shopee pada mahasiswa Fakultas Ekonomi Universitas Sarjanawiyata Tamansiswa.

2. Terdapat pengaruh positif Perceived Ease of Use terhadap Perceived of Usefulness dalam menggunakan e-commerce Shopee pada mahasiswa Fakultas Ekonomi Universitas Sarjanawiyata Tamansiswa.

3. Terdapat pengaruh positif Perceived of Usefulness terhadap Intention dalam menggunakan e-commerce Shopee pada mahasiswa Fakultas Ekonomi Universitas Sarjanawiyata Tamansiswa.

\section{DAFTAR PUSTAKA}

[1] Aditya, R., \& Wardhana, A. (2016). Pengaruh Perceived Usefulness Dan Perceived Ease Of Use Terhadap Behavioral Intention Dengan Pendekatan Technology Acceptance Model ( Tam ) Pada Pengguna Instant Messaging Line Di Indonesia. 20.

[2] Bangkara, R. P., Putu, N., \& Harta, S. (2016). Pengaruh Perceived Usefulness Dan Perceived Ease Of Use Pada Minat Penggunaan Internet Banking Dengan Attitude Toward Using Sebagai Variabel Intervening. 16, 2408-2434.

[3] Cholifah, R. N. U. R. (2020). Pengaruh Perceived Usefulness, Perceived Ease Of Use Dan Trust Terhadap Intention To Use.

[4] Juniwati. (2015). Pengaruh Perceived Ease of Use, Enjoyment dan Trust Terhadap Repurchase Intention dengan Customer Satisfaction Sebagai Intervening pada Belanja Online ( Studi Pada Mahasiswa Universitas Tanjungpura Pontianak ). 4(1), 140-156.

[5] Kanchanatanee, K., Suwanno, N., \& Jarernvongrayab, A. (2014). Effects of Attitude toward Using, Perceived Usefulness, Perceived Ease of Use and Perceived Compatibility on Intention to Use E-Marketing. Journal of Management Research, 6(3), 1. https://doi.org/10.5296/jmr.v6i3.5573

[6] Lea, E. (2018). Pengaruh Perceived Ease Of Use dan Faktor lain Terhadao Niat Kaum Milenial Dalam Menggunakan Transportasi Berbasis Aplikasi. (December), 0-18.

[7] Listya, N. (2016). Technology Acceptance Model Sebagai Penggerak Sikap Terhadap Penggunaan Aplikasi Gojek Dalam Membentuk Behavioral Intention To Use. 입법학연구, 제 13 집 1 호(May), 31-48.

[8] Mulyana, M. (2012). Consumer Behaviour: Sukses Dengan Memahami Konsumen.

[9] Nurendah, Y., Mulyana, M., \& Muanas, M. (2018). Evaluasi dan Pemetaan Minat Studi Siswa SMA dan SMK di Kota Bogor Pada Program Studi Ekonomi Syariah. JAS-PT (Jurnal Analisis Sistem Pendidikan Tinggi Indonesia), 2(2), 83-94.
Digital Marketing and Millenials

Consumers 
Digital Marketing and Millenial Consumers

10

[10] Perdana, A. S. (2019). Pengaruh Kemudahan Penggunaan Aplikasi, Pengalaman Berbelanja, Kepercayaan Konsumen, Dan Promosi Terhadap Minat Beli Mahasiswa Fkip Unila Di Situs Jual Beli Online Shopee.

[11] Priambodo, S., \& Prabawani, B. (2016). Pengaruh Persepsi Manfaat, Persepsi Kemudahan Penggunan, Dan Persepsi Risiko Terhadap Minat Menggunakan Layanan Uang Elektronik (Studi Kasus Pada Masyarakat Di Kota Semarang). Jurnal Ilmu Administrasi Bisnis, 5(2), 127-135.

[12] PUSPITASARI, I., \& BRILIANA, V. (2018). Pengaruh Perceived Ease-of-Use, Perceived Usefulness, Trust Dan Perceived Enjoyment Terhadap Repurchase Intention (Studi Kasus Pada Website Zalora Indonesia). Jurnal Bisnis Dan Akuntansi, 19(2), 171-182. https://doi.org/10.34208/jba.v19i2.270

[13] Setyani, L. A. (2014). Analisis Pengaruh Kualitas Pelayanan Dan Kepercayaan Terhadap Loyalitas Pelanggan Melalui Kepuasan Pelanggan.

[14] Suryani, W. (2019). Pengaruh Perceived Ease Of Use, Perceived Enjoyment, Dan Perceived Trust Terhadap Behavioral Intention To Use Pada Penggunaan E-Money Card.

[15] Ulaan, R. V., Pangemanan, S. S., \& Lambey, L. (2016). The Effect Of Perceived Enjoyment On Intention To Shop Online (The Study Of Faculty Of Economics And Business Sam Ratulangi University Manado). 4(1), 1137-1146.

[16] Winayu, N. Y. (2013). Pengaruh Kepercayaan, Perceived Ease Of Use Dan Perceived Usefulness Terhadap Minat Menggunakan E-Commerce Forum Jual Beli Dan Perceived Usefulness Terhadap Minat Menggunakan E-Commerce Forum Jual Beli.

[17] Yufizar, A. F. (2017). Pengaruh Experiential Marketing Dan Brand Trust Terhadap Kepuasan Konsumen Dan Loyalitas Pelanggan Hotel Grand Jatra Pekanbaru. 